\title{
RESEARCH
}

Open Access

\section{Gastric cancer with positive peritoneal cytology: survival benefit after induction chemotherapy and conversion to negative peritoneal cytology}

Massimiliano Valletti ${ }^{1 \dagger}$, Dilmurodjon Eshmuminov ${ }^{1+}$, Nicola Gnecco ${ }^{2}$, Christian Alexander Gutschow ${ }^{1}$,

Paul Magnus Schneider ${ }^{1}$ and Kuno Lehmann ${ }^{1 *}$ (D)

\begin{abstract}
Background: The optimal treatment in patients with gastric cancer and peritoneal disease remains controversial. Some guidelines indicate palliative treatment only, while others consider surgical treatment in case of positive lavage cytology $(\mathrm{CY}+)$ or limited peritoneal disease. Here, we analyzed the role of peritoneal disease in patients with gastric cancer, and the prognostic relevance of response to neoadjuvant therapy.

Methods: In this retrospective cohort analysis, we analyzed patients with adenocarcinoma of the stomach or esophago-gastric junction from a single center operated between 2011 and 2019. According to histology and lavage cytology, patients were classified into four risk groups: (A) no peritoneal disease, (B) CY+ who converted to negative lavage cytology (CY-) after neoadjuvant chemotherapy, (C) CY+ without conversion after chemotherapy, and (D) patients with visible peritoneal metastasis.

Results: Overall, $n=172$ patients were included. At initial presentation, $n=125$ (73\%) had no peritoneal disease, and about a third of patients $(n=47,27 \%)$ had microscopic or macroscopic peritoneal disease. Among them, $n=$ $14(8 \%)$ were $C Y+$ without visible peritoneal metastasis, $n=9$ converted to $C Y$ - after chemotherapy, and in $n=5$ no conversion was observed. Median overall survival was not reached in patients who had initially no peritoneal disease and in patients who converted after chemotherapy, resulting in 3-year survival rates of $65 \%$ and $53 \%$. In contrast, median overall survival was reduced to 13 months (95\% Cl 8.7-16.7) in patients without conversion and was 16 months (95\% Cl 12-20.5) in patients with peritoneal metastasis without difference between the two groups $(p=.364)$. The conversion rate from CY+ to CY - was significantly higher after neoadjuvant treatment with FLOT (5-fluorouracil plus leucovorin, oxaliplatin, and docetaxel) compared to ECF (epirubicin, cisplatin, and 5-fluorouracil) $(p=0.027)$.
\end{abstract}

\footnotetext{
* Correspondence: kuno.lehmann@usz.ch

${ }^{+}$Massimiliano Valletti and Dilmurodjon Eshmuminov share the first authorship.

${ }^{1}$ Department of Surgery and Transplantation, University Hospital Zurich, Zurich, Switzerland

Full list of author information is available at the end of the article
}

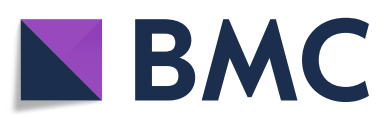

(c) The Author(s). 2021 Open Access This article is licensed under a Creative Commons Attribution 4.0 International License, which permits use, sharing, adaptation, distribution and reproduction in any medium or format, as long as you give appropriate credit to the original author(s) and the source, provide a link to the Creative Commons licence, and indicate if changes were made. The images or other third party material in this article are included in the article's Creative Commons licence, unless indicated otherwise in a credit line to the material. If material is not included in the article's Creative Commons licence and your intended use is not permitted by statutory regulation or exceeds the permitted use, you will need to obtain permission directly from the copyright holder. To view a copy of this licence, visit http://creativecommons.org/licenses/by/4.0/ The Creative Commons Public Domain Dedication waiver (http://creativecommons.org/publicdomain/zero/1.0/) applies to the data made available in this article, unless otherwise stated in a credit line to the data. 
Conclusion: Conversion of $\mathrm{CY}+$ to $\mathrm{CY}$ - after neoadjuvant chemotherapy with FLOT is a significant prognostic factor for a better overall survival. Surgical treatment in well-selected patients should therefore be considered. However, peritoneal recurrence remains frequent despite conversion, urging for a better local control.

Keywords: Gastric cancer, Peritoneal lavage cytology, Peritoneal metastasis, Neoadjuvant chemotherapy

\section{Introduction}

Gastric cancer is a leading cause of cancer death worldwide, with an estimated 5-year survival rate of $26 \%$ in Europe [1]. According to the GLOBOCAN 2018 estimates of cancer incidence, gastric cancer is the 5th most common neoplasm and the 3rd most deadly cancer worldwide, with 783,000 deaths in 2018 [2]. Due to the lack of national screening programs in Western countries, many patients are diagnosed with advanced stage disease and up to $20 \%$ present with peritoneal metastasis upon open or laparoscopic exploration [3, 4]. Peritoneal metastases have a dismal prognosis, and most patients receive palliative chemotherapy only [5]. In contrast, the relevance of microscopic disease, detectable only as $\mathrm{CY}+$ remains unclear [6]. There is an ongoing debate if these patients should undergo gastrectomy $[7,8]$, and the available national guidelines are not consistent regarding treatment recommendations. For example, the National Comprehensive Cancer Network (NCCN) gastric cancer guidelines define $\mathrm{CY}+$ as metastatic (M1) disease and recommend a palliative treatment [9], similar to the Japanese Gastric Cancer Association, which classifies positive peritoneal cytology as M1 and does not recommend surgery $[10,11]$. In contrast, European guidelines, e.g., the German S3, or the ESMO guidelines are less detailed and remain unclear, probably due to the lack of data in Western patients $[12,13]$. Another open question is how to deal with patients who had $\mathrm{CY}+$ and converted to $\mathrm{CY}$ - after neoadjuvant treatment. Reports from Japan show an improved survival of this subgroup and therefore recommend a more radical treatment after conversion to CY- $[14,15]$. The literature is scarce for Western patients [16], while novel treatment options for patients with locally advanced disease are available, e.g., the radical cytoreductive surgery (CRS) with hyperthermic intraperitoneal chemotherapy (HIPEC) [17] or the pressurized intraperitoneal aerosol chemotherapy (PIPAC) [18]. In this study, we analyzed the overall survival of gastric cancer with a focus on patients with $\mathrm{CY}+$

\section{Materials and methods Patients}

Patients with gastric cancer treated at the University Hospital of Zurich between September 2011 and December 2019 were retrospectively analyzed. All patients were discussed in an interdisciplinary tumor board.
Neoadjuvant systemic treatment was performed according to international standards. Patients received FLOT (5-fluorouracil plus leucovorin, oxaliplatin and docetaxel) or ECF (Epirubicin, cisplatin and 5-fluorouracil) depending on the preference of the treating medical oncologist. Surgery was performed with either total or subtotal gastrectomy and D2-lymphadenectomy 3 to 4 weeks after completion of neoadjuvant systemic treatment. Follow-up included clinical exams, upper endoscopy, and CT scan.

\section{Peritoneal lavage cytology}

Laparoscopy with cytology was performed to evaluate for peritoneal disease when considering chemotherapy or surgery. Suspicious macroscopic peritoneal implants detected during laparoscopy were biopsied. If peritoneal seeding was confirmed histologically, palliative treatment was considered. The second peritoneal lavage for cytology was performed after neoadjuvant systemic treatment or at the time of surgical resection. One thousand milliliters of saline was installed into the upper and lower abdomen without manipulation of the tumor. After a 10-min incubation period, all available fluid was aspirated and sent for cytological analysis. Cytological evaluation included microscopy and immunohistochemistry.

\section{Data analysis}

Statistical analysis was performed using R statistical software (version 4.0.2.). $p$-values are based on the chisquare test and Fischer's exact test for categorical variables, and ANOVA for continuous variables, and were considered statistically significant if $<0.05$. The KaplanMeier method was used to calculate survival. Groups were compared using the log-rank test. Follow-up time was defined from the date of diagnosis to the following event: 1) death or last follow-up day and 2) documented evidence of cancer recurrence by histology or imaging. Patients with CY- and clinical absence of peritoneal metastasis (negative group) were used as the control group.

\section{Results}

\section{Patient characteristics}

One hundred and seventy-two patients were analyzed with a mean follow-up of 25 ( \pm 18.1$)$ months. According to histology and lavage cytology, patients were classified into four risk groups: (A) no peritoneal disease (negative group $n=125$ ), (B) $\mathrm{CY}+$ who converted to $\mathrm{CY}$ - after 
neoadjuvant chemotherapy (converted group $n=9$ ), (C) $\mathrm{CY}+$ without conversion to $\mathrm{CY}-$ after neoadjuvant chemotherapy (non-converted group $n=5$ ), and (D) patients with visible peritoneal metastasis $(n=33)$. Patient characteristics are shown in Table 1.

\section{Response to neoadjuvant chemotherapy}

All patients with no peritoneal disease and conversion to $\mathrm{CY}$ - and those who remained $\mathrm{CY}+$ underwent radical surgery. Patients with positive peritoneal cytology received FLOT in $79 \%(11 / 14)$ and ECF in $21 \%(3 / 14)$ of patients. We observed a higher conversion rate to CY- after treatment with FLOT compared to ECF $(9 / 11$ vs. $0 / 3 ; p=.027)$. Progression during chemotherapy was observed in five patients $(n$ $=3$ patients with ECF, $n=2$ with FLOT), resulting in a $\mathrm{CY}+$ after neoadjuvant systemic treatment. Among 33 patients with peritoneal metastasis, 28 received palliative chemotherapy and five patients underwent palliative surgery.

\section{Overall survival}

Conversion to $\mathrm{CY}$ - after neoadjuvant chemotherapy resulted in an improved overall survival (Fig. 1). Median overall survival was not reached in patients without peritoneal disease and in patients who converted to $\mathrm{CY}-$ after chemotherapy, resulting in 3-year survival rates of $65 \%$ and $53 \%$. Median overall survival was reduced to 13 months (95\% CI 8.7-16.7) in patients without conversion and was 16 months (95\% CI 12-20.5) in patients with peritoneal metastasis without difference between the two groups $(p=0.36)$. Overall survival of patients

Table 1 Patient characteristics

\begin{tabular}{|c|c|c|c|c|c|}
\hline & Negative, $n=125$ & Converted negative, $n=9$ & Not converted, $n=5$ & Peritoneal metastasis, $n=33$ & $p$ \\
\hline Age (years) & $61 \pm 13$ & $54 \pm 9$ & $64 \pm 9$ & $53 \pm 15$ & 0.016 \\
\hline Gender m/f & $88(70 \%) / 7(30 \%)$ & $4(44 \%) / 5(56 \%)$ & $3(60 \%) / 2(40 \%)$ & $21(64 \%) / 2(36 \%)$ & 0.390 \\
\hline \multicolumn{6}{|l|}{ Tumor location } \\
\hline AEG & $61(49 \%)$ & $5(55 \%)$ & $5(100 \%)$ & 10 (30\%) & \multirow[t]{2}{*}{0.021} \\
\hline Gastric & $64(51 \%)$ & $4(45 \%)$ & 0 & 23 (70\%) & \\
\hline \multicolumn{6}{|l|}{ Chemotherapy } \\
\hline FLOT & $62(50 \%)$ & $9(100 \%)$ & $2(40 \%)$ & $19(58 \%)$ & \multirow[t]{4}{*}{$>0.001$} \\
\hline ECF & $13(10 \%)$ & 0 & $3(60 \%)$ & $4(12 \%)$ & \\
\hline Others & 0 & 0 & 0 & $3(9 \%)$ & \\
\hline No chemotherapy & $50(40 \%)$ & 0 & 0 & $7(21 \%)$ & \\
\hline \multicolumn{6}{|l|}{ pT or ypT } \\
\hline T0 & $7(5 \%)$ & $1(11 \%)$ & 0 & NA & \multirow[t]{5}{*}{0.141} \\
\hline T1 & $36(29 \%)$ & 0 & 0 & & \\
\hline $\mathrm{T} 2$ & $20(16 \%)$ & $1(11 \%)$ & 0 & & \\
\hline T3 & $51(41 \%)$ & $7(78 \%)$ & $4(80 \%)$ & & \\
\hline T4 & $11(9 \%)$ & 0 & $1(20 \%)$ & & \\
\hline Positive lymph nodes & $64(51 \%)$ & $5(55 \%)$ & $5(100 \%)$ & NA & 0.109 \\
\hline Mean retrieved LN & $42 \pm 20$ & $56 \pm 11$ & $36 \pm 11$ & NA & 0.105 \\
\hline \multicolumn{6}{|l|}{ Grading $^{a}$} \\
\hline G1 & $3(3 \%)$ & 0 & 0 & 0 & \multirow[t]{3}{*}{0.772} \\
\hline G2 & $25(26 \%)$ & $1(11 \%)$ & $1(20 \%)$ & $2(13 \%)$ & \\
\hline G3 & 67 (71\%) & $8(89 \%)$ & $4(80 \%)$ & $13(87 \%)$ & \\
\hline \multicolumn{6}{|l|}{ Lauren type $^{a}$} \\
\hline Intestinal & $64(61 \%)$ & $4(45 \%)$ & $4(80 \%)$ & $6(22 \%)$ & \multirow[t]{2}{*}{0.002} \\
\hline Diffuse & 41 (39\%) & $5(55 \%)$ & $1(20 \%)$ & $21(78 \%)$ & \\
\hline
\end{tabular}

Patient characteristics are summarized according to the presence or absence of peritoneal disease during staging laparoscopy. While $n=125$ patients had no peritoneal disease, $n=9$ converted to $\mathrm{CY}$ - and $n=5$ remained $\mathrm{CY}+$ after neoadjuvant chemotherapy. Macroscopic peritoneal metastasis was present in $n=$ 33 patients

$A E G$ adenocarcinoma of the esophago-gastric junction, $L N$ lymph nodes, NA not available

${ }^{a}$ The data for some patients is missing. $p$-values are based on the chi-square test and Fisher's exact test for categorical variables and ANOVA

for continuous variables 

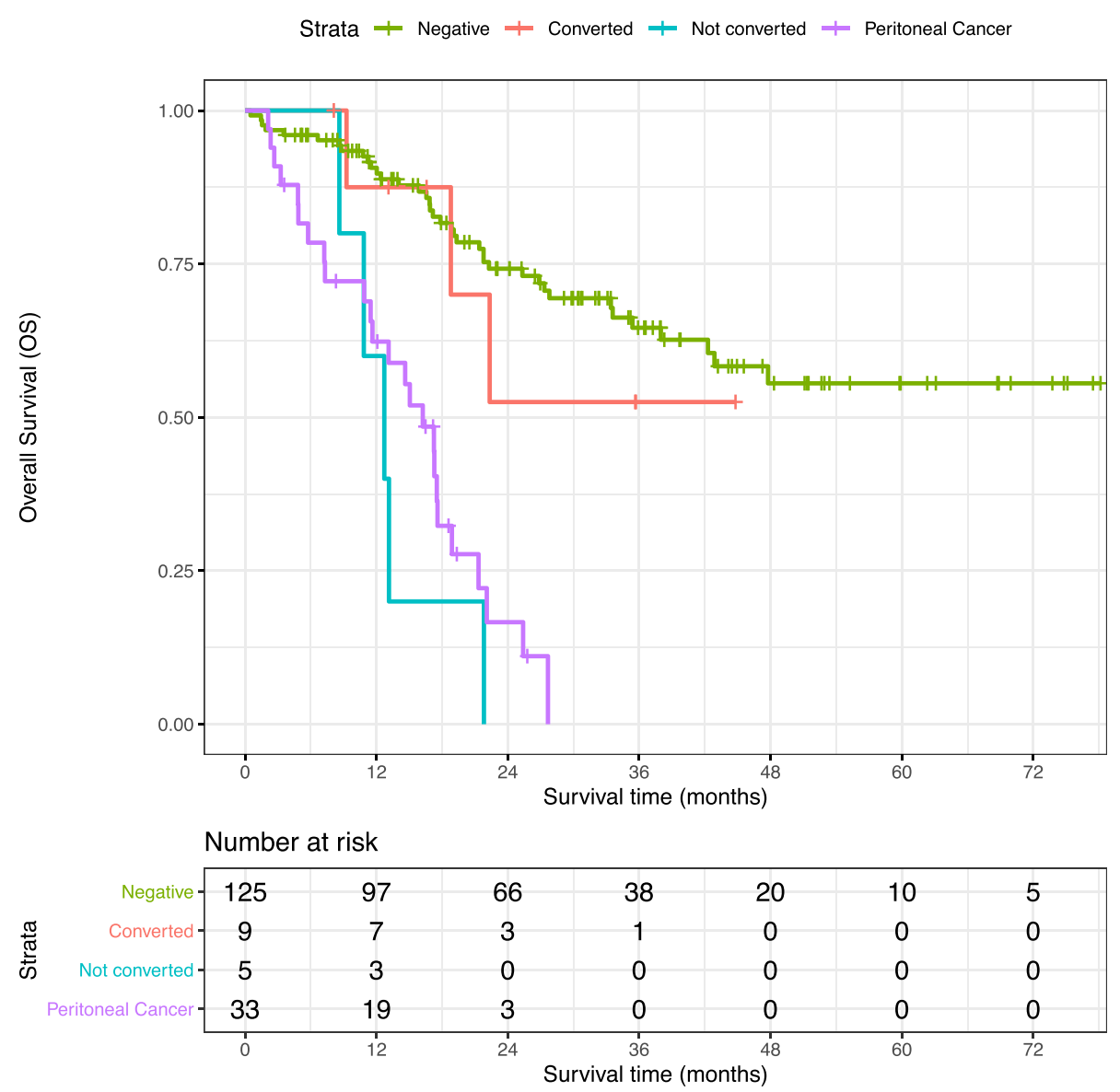

Fig. 1 Overall survival. Kaplan-Meier plot for patients according to their peritoneal disease status. Median OS of patients without peritoneal disease and of patients who did convert after neoadjuvant therapy was not reached. In contrast, median OS was reduced to 13 months (95\% Cl 8.7-16.7) in patients without conversion and was 16 months (95\% Cl 12-20.5) in patients with peritoneal metastasis without difference between the two groups $(p=.364)$

after conversion to $\mathrm{CY}$ - was significantly better compared to patients who did not convert to $\mathrm{CY}-$ after chemotherapy $(p=0.01)$.

\section{Disease-free survival}

Median disease-free survival was not reached in patients without peritoneal disease and was 21.7 months after conversion, resulting in $82 \%$ and $64 \%$ of patients remaining free from disease at 1-year follow-up (Fig. 2). In contrast, median disease-free survival at 1 year was only $20 \%$ in patients with persistent positive lavage cytology, highlighting a rapid disease progression beyond positive lavage cytology in the majority of the patients. Over the follow-up time of 24 months, peritoneal recurrence was finally observed in 25\% (31/125) of patients who had no peritoneal disease upfront and in 55\% (5/9) of patients who converted to $\mathrm{CY}$ - after neoadjuvant treatment.

\section{Discussion}

Peritoneal metastasis is one of the most common forms of metastasis in patients with gastric cancer reported in the literature between 10 and 20\% [3, 4, 19]. Therefore, an accurate diagnosis remains crucial for prognostic evaluations and therapeutic decisions. Staging laparoscopy and peritoneal cytology are recommended tools that allow to detect occult peritoneal spreading, especially in patients in an early stage of the disease, presenting in almost $11 \%$ of the cases with a positive peritoneal cytology $[20,21]$. In this study, we could confirm the prognostic impact of peritoneal disease and we could demonstrate that patients who converted to $\mathrm{CY}$ - after systemic treatment have a better cumulative survival compared with patients demonstrating persisting $\mathrm{CY}+$. However, the high incidence of peritoneal recurrence despite response to neoadjuvant chemotherapy remains a problem and underlines the need for better local control and novel strategies. 

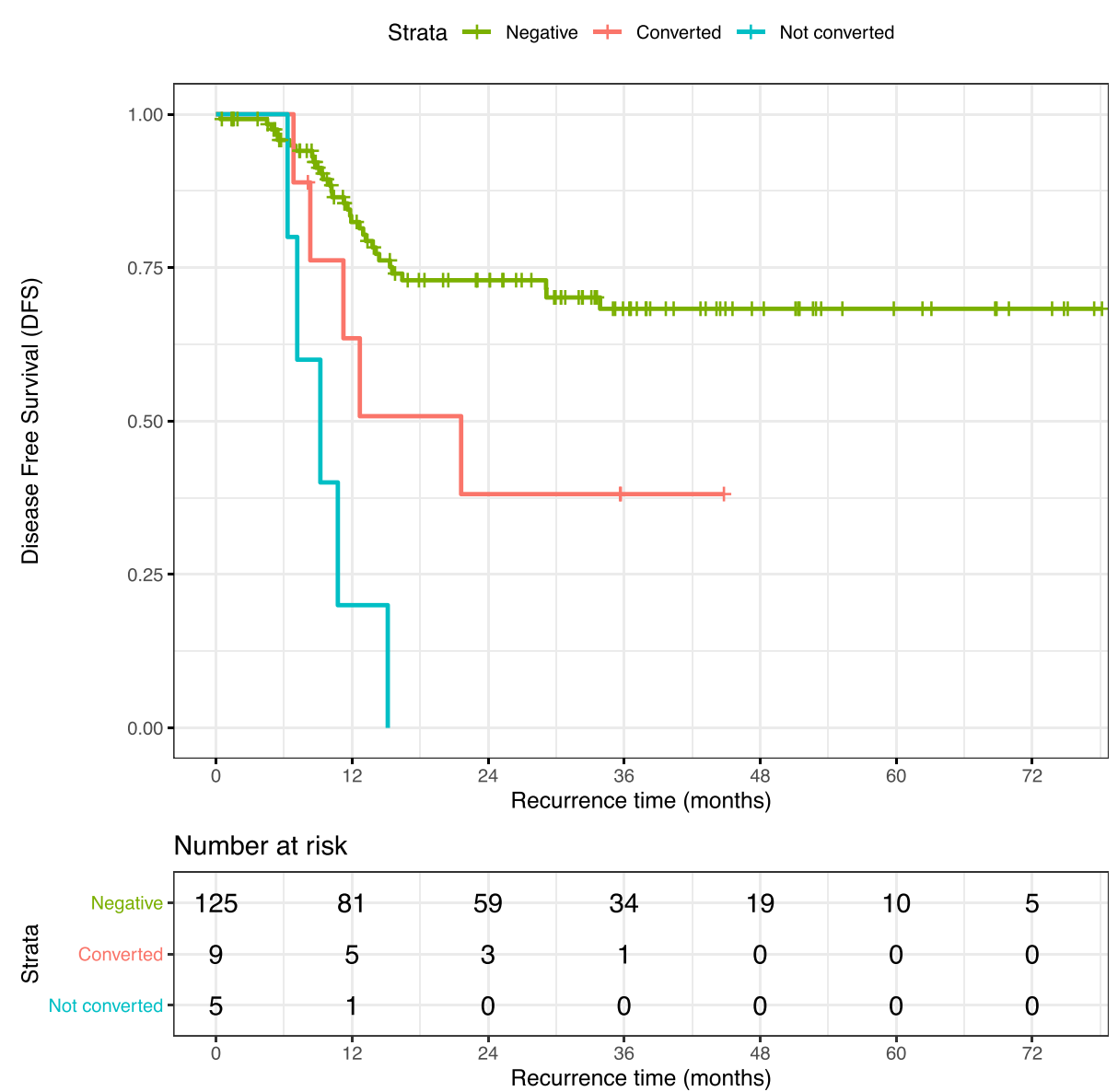

Fig. 2 Disease-free survival. Kaplan-Meier plot for patients according to their peritoneal disease status. Median DFS at 1 year was $82 \%$ for patients without peritoneal disease and 64\% for patients after conversion, with a median DFS not reached in the negative group and $21.7 \mathrm{months}(95 \% \mathrm{Cl}$ 7.9-35) in the converted group. In contrast, DFS at 1 year was only 20\% in patients with persistent positive lavage cytology after systemic therapy

The role of surgery in patients with conversion after neoadjuvant systemic treatment is controversially reported in the current literature. A systematic review revealed only three studies with neoadjuvant systemic treatment in patients with positive peritoneal cytology [6], and the time point of peritoneal cytology and inclusion criteria varied considerably among these three studies. For example, one study reported 39 patients with positive peritoneal cytology without peritoneal metastasis with a median survival of 12.8 months [22]. In this study, peritoneal cytology was performed only prior to neoadjuvant systemic treatment and not thereafter. Therefore, a difference between patients with or without conversion after neoadjuvant systemic treatment was not analyzed. Another group reported 48 patients with repeated cytology, and among them, 27 converted to negative cytology, while 21 did not [8]. They observed no benefit of surgery after conversion to negative lavage cytology. In two other studies, the benefit of surgery in patients after conversion to negative lavage cytology was clearly demonstrated $[14,16]$. These two studies highlight the potential risk of developing $\mathrm{CY}+$ during neoadjuvant systemic treatment in patients who were initially $\mathrm{CY}-$. Unfortunately, there are no known risk factors predicting poor response to neoadjuvant treatment. Such patients would profit from an early response evaluation and discontinuation of neoadjuvant systemic treatment [23]. Some authors suggest that nonresponders would profit from early surgery. However, in our study, we observed that patients without conversion to $\mathrm{CY}$ - after systemic treatment had a very bad prognosis, on average worse than patients with macroscopic peritoneal cancer. Despite the relatively small number of patients in our series and the absence of statistical difference between the two groups, this finding likely reflects the probably unfavorable and rapid tumor biology in this situation and should call for caution.

Regarding neoadjuvant treatment, in the past decades, many advances in perioperative chemotherapy for gastric cancer have been made. For example, two clinical trials which represented landmarks regarding the topic were the MAGIC trial and the French FNCLCC/FFCD 9703 
study [24, 25]. Despite a great effort, the outcome for gastric cancer remained insufficient. Furthermore, several studies reported improved survival rates with the addition of taxane-based regimens in patients with advanced gastric cancer as well as with peritoneal metastasis. For example, Wang et al. described an overall response rate of $50 \%$ for taxane-based combination chemotherapy in patients with advanced gastric cancer [26]. Moreover, Fujiwara et al. described a highly effective and well-tolerated combination of intraperitoneal and systemic chemotherapy based on docetaxel, showing that $59 \%$ of the patients displayed major response and $56 \%$ showed negative results on peritoneal cytology and no macroscopic peritoneal metastasis after treatment [27]. Another interesting work by Fushida et al. shows an overall response rate of $22 \%$ and a conversion to CYin $81 \%$ of the patients after administration of intraperitoneal docetaxel plus S-1 for gastric cancer with peritoneal carcinomatosis [28]. In one randomized phase II trial, docetaxel in combination with 5-fluorouracil demonstrated a better overall response rate compared to ECF in patients with advanced cancer (37.8\% vs. $35 \%)$ [29]. In another phase II randomized trial, the addition of cisplatin to docetaxel and 5-fluorouracil showed a favoring effect with improved response rates of docetaxel in combination with cisplatin and 5-fluorouracil over ECF or docetaxel with 5-fluorouracil, although the study was not powered sufficiently to show superiority (36.6\% vs. $25 \%$ vs. $18.5 \%$ ) [30]. Recently, Al-Batran and his group set a new cornerstone with the FLOT4 trial, demonstrating the superiority of FLOT over ECF/X as perioperative chemotherapy in locally advanced gastric cancer (complete and subtotal regression rate of $37 \%$ vs. $23 \% p$ $=0.02$ ) [31]. In the setting of gastric cancer with CY+, there is to our knowledge a lack of prospective randomized data about the superiority of one chemotherapeutic regimen compared to another so far. In our series, we observed a conversion rate from $\mathrm{CY}+$ to $\mathrm{CY}$ - with FLOT of $82 \%$ (9/11) and no patient converted under ECF $(0 / 3)$. Based on the trend towards a higher conversion rate in our series and on the available data about advanced gastric cancer, we conclude that patients with gastric cancer with $\mathrm{CY}+$ should benefit from the FLOT regimen in the neoadjuvant setting. We are aware of our limited numbers of patients with $\mathrm{CY}_{+}$, which is itself a rare condition and we think that further multicentric studies with larger cohorts of patients should be performed to achieve stronger results.

Another interesting observation is the recurrence pattern, which obviously depends on the peritoneal cytology status. It is well known that advanced stage gastric cancer is an independent prognostic factor of peritoneal recurrence, which is reported in the current literature ranging from 8 to $62 \%$ [14, 32-34]. In contrast, early- stage gastric cancer shows more often hematogenous recurrence patterns [35], and similarly, patients with CYseem to have less peritoneal recurrence [14, 34]. In our series, recurrence rates in patients without peritoneal disease are comparable with the current literature [14]. We would like to highlight that patients with $\mathrm{CY}+$ at any time had a higher risk to develop peritoneal recurrence, which indicates the need for adjuvant or additive therapy. Even for the patients who did convert to $\mathrm{CY}-$, the recurrence rates are higher compared to the negative group. Although the mechanisms governing the occurrence of peritoneal metastasis and peritoneal recurrence remain unclear, we can postulate that based on the "seed and soil theory" the higher rate of peritoneal recurrence in the converted group is likely due to tumor cells that seed in the peritoneum and migrate through the basement membrane to the subperitoneal space, surviving therefore after neoadjuvant treatment and remaining undetected during peritoneal lavage [20]. Indeed, there is a meta-analysis of 20 randomized controlled trials which demonstrates the benefit of an adjuvant intraperitoneal chemotherapy after radical surgery in advanced gastric cancer, although a separate analysis investigating the role of adjuvant intraperitoneal chemotherapy in patients with $\mathrm{CY}+$ and no visible peritoneal metastasis was not performed [36]. Recently, a phase II trial using a more aggressive approach combining CRS, gastrectomy, and HIPEC demonstrated encouraging results in patients with minimal peritoneal metastasis from gastric cancer or positive lavage cytology [37]. Some authors recommend even prophylactic HIPEC at the time of resection for advanced stage gastric cancer without peritoneal disease, highlighting the importance of reducing the risk of occult peritoneal dissemination during surgery in order to prevent future recurrence [38]. Currently, we may speculate that additive locoregional treatment in patients with $\mathrm{CY}+$ might be considered in all patients undergoing resection, irrespective of their conversion status.

Another important issue that should be considered is the predicting factors that meant to achieve the best outcome possible. Our findings suggest that conversion of $\mathrm{CY}+$ to $\mathrm{CY}$ - could be a prognostic factor for a better outcome. In the current literature, we can find some other important predictors that should be considered in the therapeutic decision-making. For example, peritoneal carcinomatosis itself appears to be a major driver of complications and dismal outcome for surgical gastrojejunostomy and should call for caution in the surgical strategy [39]. Moreover, an interesting study by Chen including 518 patients highlights the importance of the body mass index as another predicting factor for patients who have gastric cancer with peritoneal dissemination, especially in those who received palliative chemotherapy [40]. Other studies showed for example that lymphopenia and thrombocytosis were predictive factors 
for peritoneal seeding $[41,42]$. Furthermore, recent studies try to identify new predicting factors such as the systemic immune-inflammation index aiming for a better oncological outcome and quality of life of our patients [43].

We would like to acknowledge the limitations of this study, which is a monocentric retrospective study. Furthermore, our analysis is based on a small number of patients with $\mathrm{CY}+$ and without macroscopic peritoneal disease.

In conclusion, the overall survival of patients who convert to $\mathrm{CY}$ - after neoadjuvant chemotherapy may be superior compared to non-converted patients. Surgical treatment in well-selected patients should therefore be considered. However, peritoneal recurrence remains frequent despite conversion, urging for a better local control.

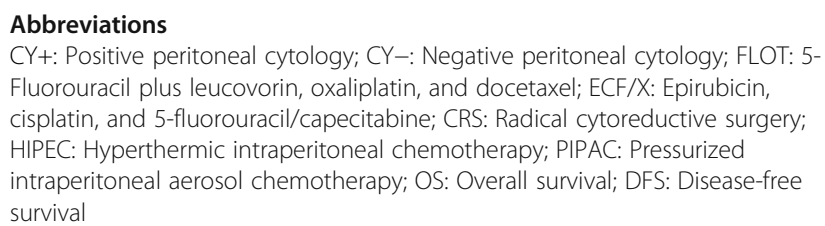

\section{Abbreviations}

CY+: Positive peritoneal cytology; CY-: Negative peritoneal cytology; FLOT: 5Fluorouracil plus leucovorin, oxaliplatin, and docetaxel; ECF/X: Epirubicin, cisplatin, and 5-fluorouracil/capecitabine; CRS: Radical cytoreductive surgery; HIPEC: Hyperthermic intraperitoneal chemotherapy; PIPAC: Pressurized intraperitoneal aerosol chemotherapy; OS: Overall survival; DFS: Disease-free survival

\section{Acknowledgements}

Not applicable

\section{Authors' contributions}

$\mathrm{MV}, \mathrm{DE}$, and $\mathrm{KL}$ were major contributors in writing the manuscript. NG analyzed the patient data and performed the statistical analysis. Contribution in reviewing the manuscript was by CG and PMS. All authors read and approved the final manuscript.

\section{Funding}

The authors have no funding to declare.

\section{Availability of data and materials}

The datasets used and analyzed during the current study are available from the corresponding author on reasonable request.

\section{Declarations}

\section{Ethics approval and consent to participate}

All procedures followed were in accordance with the ethical standards of the responsible committee on human experimentation (institutional and national) and with the Helsinki Declaration of 1964 and later versions. The local independent ethics committee of Cantons Zurich, Switzerland, has approved the retrospective study protocol (local registration number PB_2016-00769).

\section{Consent for publication}

Informed consent for research purpose with patient data was obtained for all patients.

\section{Competing interests}

The authors declare that they have no competing interests.

\section{Author details}

'Department of Surgery and Transplantation, University Hospital Zurich, Zurich, Switzerland. ${ }^{2}$ Research Center for Statistics, University of Geneva, Geneva, Switzerland.
Received: 17 May 2021 Accepted: 27 July 2021

Published online: 17 August 2021

\section{References}

1. Cancer Research UK. https://www.cancerresearchuk.org/healthprofessional/ cancer-statistics/statistics-by-cancer-type/stomach-cancer/survival\#headingTwo. Accessed Aug 2020.

2. Bray F, Ferlay J, Soerjomataram I, Siegel RL, Torre LA, Jemal A. Global cancer statistics 2018: GLOBOCAN estimates of incidence and mortality worldwide for 36 cancers in 185 countries. CA Cancer J Clin. 2018;68(6):394-424.

3. Braam HJ, Schellens JH, Boot H, van Sandick JW, Knibbe CA, Boerma D, et al. Selection of chemotherapy for hyperthermic intraperitoneal use in gastric cancer. Crit Rev Oncol Hematol. 2015;95(3):282-96.

4. Lehmann K, Eshmuminov D, Bauerfeind P, Gubler C, Veit-Haibach P, Weber A, et al. (18)FDG-PET-CT improves specificity of preoperative lymph-node staging in patients with intestinal but not diffuse-type esophagogastric adenocarcinoma. Eur J Surg Oncol. 2017;43(1):196-202.

5. Yonemura $Y$, Endou Y, Sasaki T, Hirano M, Mizumoto A, Matsuda T, et al. Surgical treatment for peritoneal carcinomatosis from gastric cancer. Eur J Surg Oncol. 2010;36(12):1131-8.

6. Cabalag CS, Chan ST, Kaneko Y, Duong CP. A systematic review and metaanalysis of gastric cancer treatment in patients with positive peritoneal cytology. Gastric Cancer. 2015;18(1):11-22

7. Okabe H, Sakai Y. Gastrectomy for patients with positive peritoneal cytology: comments on the article "Positive peritoneal cytology in patients with gastric cancer: natural history and outcome of 291 patients". Ann Surg Oncol. 2011;18(Suppl 3):S211-2 author reply S3-4.

8. Mezhir JJ, Shah MA, Jacks LM, Brennan MF, Coit DG, Strong VE. Positive peritoneal cytology in patients with gastric cancer: natural history and outcome of 291 patients. Ann Surg Oncol. 2010;17(12):3173-80.

9. National Comprehensive Cancer Network. Clinical Practice Guidelines in Oncology (NCCN Guidelines ${ }^{\oplus}$ ). Gastric Cancer. Version 3.2020. Available online: https://www.nccn.org/store/login/login.aspx?ReturnURL=https:// www.nccn.org/professionals/physician_gls/pdf/gastric.pdf. Accessed Aug 2020.

10. Japanese Gastric Cancer A. Japanese classification of gastric carcinoma: 3rd English edition. Gastric Cancer. 2011;14(2):101-12.

11. Japanese Gastric Cancer A. Japanese gastric cancer treatment guidelines 2014 (ver. 4). Gastric Cancer. 2017;20(1):1-19.

12. Leitlinienprogramm Onkologie (Deutsche Krebsgesellschaft, Deutsche Krebshilfe, AWMF):S3-Leitlinie Magenkarzinom, Langversion 2.0, 2019 AWMF Registernummer: 032/009OL. http://www.leitlinienprogramm-onkologie.de/ leitlinien/magenkarzinom/. Accessed Aug 2020.

13. Smyth EC, Verheij M, Allum W, Cunningham D, Cervantes A, Arnold D, et al. Gastric cancer: ESMO Clinical Practice Guidelines for diagnosis, treatment and follow-up. Ann Oncol. 2016;27(suppl 5):v38-49.

14. Aizawa M, Nashimoto A, Yabusaki H, Nakagawa S, Matsuki A, Homma K, et al. The clinical significance of potentially curative resection for gastric cancer following the clearance of free cancer cells in the peritoneal cavity by induction chemotherapy. Surg Today. 2015;45(5):611-7.

15. Yasufuku I, Nunobe S, Ida S, Kumagai K, Ohashi M, Hiki N, et al. Conversion therapy for peritoneal lavage cytology-positive type 4 and large type 3 gastric cancer patients selected as candidates for $\mathrm{R} 0$ resection by diagnostic staging laparoscopy. Gastric Cancer. 2020;23(2):319-27.

16. Lorenzen S, Panzram B, Rosenberg R, Nekarda H, Becker K, Schenk U, et al. Prognostic significance of free peritoneal tumor cells in the peritoneal cavity before and after neoadjuvant chemotherapy in patients with gastric carcinoma undergoing potentially curative resection. Ann Surg Oncol. 2010;17(10):2733-9.

17. Bonnot PE, Piessen G, Kepenekian V, Decullier E, Pocard M, Meunier B, et al. Cytoreductive surgery with or without hyperthermic intraperitoneal chemotherapy for gastric cancer with peritoneal metastases (CYTO-CHIP study): a propensity score analysis. J Clin Oncol. 2019;37(23):2028-40.

18. Nowacki M, Alyami M, Villeneuve L, Mercier F, Hubner M, Willaert W, et al. Multicenter comprehensive methodological and technical analysis of 832 pressurized intraperitoneal aerosol chemotherapy (PIPAC) interventions performed in 349 patients for peritoneal carcinomatosis treatment: an international survey study. Eur J Surg Oncol. 2018:44(7):991-6.

19. Klos D, Riško J, Loveček M, Skalický P, Svobodová I, Krejčí D, et al. Trends in peritoneal surface malignancies: evidence from a Czech nationwide population-based study. World J Surg Oncol. 2019;17(1):182. 
20. Wang Z, Chen JQ, Liu JL, Tian L. Issues on peritoneal metastasis of gastric cancer: an update. World J Surg Oncol. 2019;17(1):215.

21. Allen CJ, Blumenthaler AN, Das P, Minsky BD, Blum M, Roy-Chowdhuri S, et al. Staging laparoscopy and peritoneal cytology in patients with early stage gastric adenocarcinoma. World J Surg Oncol. 2020;18(1):39.

22. Badgwell B, Cormier JN, Krishnan S, Yao J, Staerkel GA, Lupo PJ, et al. Does neoadjuvant treatment for gastric cancer patients with positive peritoneal cytology at staging laparoscopy improve survival? Ann Surg Oncol. 2008; 15(10):2684-91.

23. Ott K, Weber WA, Lordick F, Becker K, Busch R, Herrmann K, et al. Metabolic imaging predicts response, survival, and recurrence in adenocarcinomas of the esophagogastric junction. J Clin Oncol. 2006;24(29):4692-8.

24. Cunningham D, Allum WH, Stenning SP, Thompson JN, Van de Velde CJ, Nicolson $\mathrm{M}$, et al. Perioperative chemotherapy versus surgery alone for resectable gastroesophageal cancer. N Engl J Med. 2006;355(1):11-20.

25. Ychou M, Boige V, Pignon JP, Conroy T, Bouché O, Lebreton G, et al. Perioperative chemotherapy compared with surgery alone for resectable gastroesophageal adenocarcinoma: an FNCLCC and FFCD multicenter phase III trial. J Clin Oncol. 2011;29(13):1715-21.

26. Wang F, Wang Z, Zhou N, An X, Xu R, He Y, et al. Phase II study of biweekly paclitaxel plus infusional 5 -fluorouracil and leucovorin as first-line chemotherapy in patients with advanced gastric cancer. Am J Clin Oncol. 2011;34(4):401-5.

27. Fujiwara Y, Takiguchi S, Nakajima K, Miyata H, Yamasaki M, Kurokawa Y, et al. Neoadjuvant intraperitoneal and systemic chemotherapy for gastric cance patients with peritoneal dissemination. Ann Surg Oncol. 2011;18(13):372631.

28. Fushida S, Kinoshita J, Kaji M, Hirono Y, Goda F, Yagi Y, et al. Phase I/II study of intraperitoneal docetaxel plus S-1 for the gastric cancer patients with peritoneal carcinomatosis. Cancer Chemother Pharmacol. 2013;71(5):126572.

29. Thuss-Patience PC, Kretzschmar A, Repp M, Kingreen D, Hennesser D, Micheel $S$, et al. Docetaxel and continuous-infusion fluorouracil versus epirubicin, cisplatin, and fluorouracil for advanced gastric adenocarcinoma: a randomized phase II study. J Clin Oncol. 2005;23(3):494-501.

30. Roth AD, Fazio N, Stupp R, Falk S, Bernhard J, Saletti P, et al. Docetaxel, cisplatin, and fluorouracil; docetaxel and cisplatin; and epirubicin, cisplatin, and fluorouracil as systemic treatment for advanced gastric carcinoma: a randomized phase II trial of the Swiss Group for Clinical Cancer Research. J Clin Oncol. 2007;25(22):3217-23.

31. Al-Batran SE, Hofheinz RD, Pauligk C, Kopp HG, Haag GM, Luley KB, et al. Histopathological regression after neoadjuvant docetaxel, oxaliplatin, fluorouracil, and leucovorin versus epirubicin, cisplatin, and fluorouracil or capecitabine in patients with resectable gastric or gastro-oesophageal junction adenocarcinoma (FLOT4-AIO): results from the phase 2 part of a multicentre, open-label, randomised phase 2/3 trial. Lancet Oncol. 2016; 17(12):1697-708

32. Moon YW, Jeung HC, Rha SY, Yoo NC, Roh JK, Noh SH, et al. Changing patterns of prognosticators during 15-year follow-up of advanced gastric cancer after radical gastrectomy and adjuvant chemotherapy: a 15-year follow-up study at a single korean institute. Ann Surg Oncol. 2007;14(10): 2730-7.

33. Schwarz RE, Zagala-Nevarez K. Recurrence patterns after radical gastrectomy for gastric cancer: prognostic factors and implications for postoperative adjuvant therapy. Ann Surg Oncol. 2002;9(4):394-400.

34. Kang KK, Hur H, Byun CS, Kim YB, Han SU, Cho YK. Conventional cytology is not beneficial for predicting peritoneal recurrence after curative surgery for gastric cancer: results of a prospective clinical study. J Gastric Cancer. 2014; 14(1):23-31

35. Li JH, Zhang SW, Liu J, Shao MZ, Chen L. Review of clinical investigation on recurrence of gastric cancer following curative resection. Chin Med J. 2012; 125(8):1479-95.

36. Coccolini F, Cotte E, Glehen O, Lotti M, Poiasina E, Catena F, et al. Intraperitoneal chemotherapy in advanced gastric cancer. Meta-analysis of randomized trials. Eur J Surg Oncol. 2014;40(1):12-26.

37. Badgwell B, Ikoma N, Murphy MB, Wang X, Estrella J, Roy-Chowdhuri S, Das P, Minsky BD, Lano E, Song S, Mansfield P, Ajani J. A Phase II Trial of Cytoreduction, Gastrectomy, and Hyperthermic Intraperitoneal Perfusion with Chemotherapy for Patients with Gastric Cancer and Carcinomatosis or Positive Cytology. Ann Surg Oncol. 2021;28(1):258-64. https://doi.org/10.124 5/s10434-020-08739-5. Epub 2020 Jun 17.
38. Beeharry MK, Zhang TQ, Liu WT, Gang ZZ. Optimization of perioperative approaches for advanced and late stages of gastric cancer: clinical proposal based on literature evidence, personal experience, and ongoing trials and research. World I Surg Oncol. 2020;18(1):51.

39. Bednarsch J, Czigany Z, Heise D, Zimmermann H, Boecker J, Ulmer TF, et al. Influence of peritoneal carcinomatosis on perioperative outcome in palliative gastric bypass for malignant gastric outlet obstruction - a retrospective cohort study. World J Surg Oncol. 2020;18(1):25.

40. Chen S, Nie RC, OuYang LY, Li YF, Xiang J, Zhou ZW, et al. Body mass index (BMI) may be a prognostic factor for gastric cancer with peritoneal dissemination. World J Surg Oncol. 2017:15(1):52.

41. Chen XD, Mao CC, Wu RS, Zhang WT, Lin J, Sun XW, et al. Use of the combination of the preoperative platelet-to-lymphocyte ratio and tumor characteristics to predict peritoneal metastasis in patients with gastric cancer. PLoS One. 2017:12(4):e0175074.

42. Ohi M, Mori K, Toiyama Y, Mohri Y, Okigami M, Yasuda H, et al. Preoperative prediction of peritoneal metastasis in gastric cancer as an indicator for neoadjuvant treatment. Anticancer Res. 2015;35(6):3511-8.

43. Inoue H, Kosuga T, Kubota T, Konishi H, Shiozaki A, Okamoto K, et al. Significance of a preoperative systemic immune-inflammation index as a predictor of postoperative survival outcomes in gastric cancer. World J Surg Oncol. 2021;19(1):173.

\section{Publisher's Note}

Springer Nature remains neutral with regard to jurisdictional claims in published maps and institutional affiliations.
Ready to submit your research? Choose BMC and benefit from:

- fast, convenient online submission

- thorough peer review by experienced researchers in your field

- rapid publication on acceptance

- support for research data, including large and complex data types

- gold Open Access which fosters wider collaboration and increased citations

- maximum visibility for your research: over $100 \mathrm{M}$ website views per year

At BMC, research is always in progress.

Learn more biomedcentral.com/submissions 